\title{
Adult neurogenesis in a psychopathological mouse model of trait anxiety and comorbid depression-like behavior: effect of antidepressants
}

\author{
Anupam Sah ${ }^{1}$, Stefano Gaburro1, Claudia Schmuckermair ${ }^{1}$, \\ Simone B Sartori ${ }^{1}$, Markus Hauschild ${ }^{1}$, Ludwig Czibere ${ }^{2}$, Regina Irschick ${ }^{3}$, \\ Lars Klimaschewski ${ }^{3}$, Rainer Landgraf ${ }^{2}$ and Nicolas Singewald*1
}

\begin{abstract}
Address: ${ }^{1}$ Department of Pharmacology and Toxicology, Institute of Pharmacy and Center for Molecular Biosciences Innsbruck (CMBI), University of Innsbruck, 6020 Innsbruck, Austria, ${ }^{2}$ Max Planck Institute of Psychiatry, 80804 Munich, Germany and ${ }^{3}$ Division of Neuroanatomy, Innsbruck Medical University, 6020 Innsbruck, Austria
\end{abstract}

Email: Nicolas Singewald* - nicolas.singewald@uibk.ac.at

* Corresponding author

from I5th Scientific Symposium of the Austrian Pharmacological Society (APHAR) Joint meeting with the Hungarian Society of Experimental and Clinical Pharmacology (MFT) and the Slovenian Pharmacological Society (SDF)

Graz, Austria. 19-21 November 2009

Published: 12 November 2009

BMC Pharmacology 2009, 9(Suppl 2):A19 doi:|0.1|86/I47|-2210-9-S2-A|9

This abstract is available from: http://www.biomedcentral.com//47I-22I0/9/S2/AI9

(C) 2009 Sah et al; licensee BioMed Central Ltd.

\section{Background}

Evidence has been provided linking neurogenesis to mood disorders. Notably, it has been shown that chronic experimental stress resulting in enhanced depression-like behavior decreases neurogenesis in the dentate gyrus (DG), while antidepressants reverse these stress-induced effects. However, in most studies "normal" animals reflecting physiology rather than pathophysiology are used. Therefore, we aimed to investigate neurogenesis in the DG of a mouse model of high-trait anxiety and comorbid depression (HAB), which mimics important features of human psychopathology, and their normal anxiety/ depression (NAB) controls.

\section{Methods}

BrdU (5-bromo-2'-deoxyuridine) was administered to female HABs and NABs. Mice were sacrificed at 15 and 42 days post BrdU to study cell proliferation and survival respectively. At $42 \mathrm{~d}$ the mice were subjected to a forced swim test. Double labelling of BrdU and c-Fos (a marker for neuronal activation) was performed to observe if newborn cells functionally integrated into the DG network. Furthermore, effects of the selective serotonin reuptake inhibitor (SSRI) fluoxetine on depression-like behavior and cell survival were assessed. Finally, gene array studies were conducted in the DG.

\section{Results}

Compared to NABs, HAB mice displayed enhanced depression-like behavior in the forced swim test and reduced newborn cell proliferation and survival in the DG. Double-labelling of BrdU and c-Fos revealed that some of the newborn cells in the survival paradigm functionally integrated in NABs, while no such evidence was found in HABs. Gene array studies revealed lower abundance of cyclin-dependent kinase 5 (Cdk5) and brainderived neurotrophic factor (BDNF) in HABs which might contribute to reduced neurogenesis. Finally, although chronic treatment with fluoxetine reduced the depressionlike behavior exclusively in female HABs, it did not alter cell survival or functional integration of newborn neurons in the DG.

\section{Conclusion}

Taken together, the enhanced depression-like behavior in a psychopathological animal model is accompanied by 
decreased hippocampal neurogenesis as well as BDNF and CdK5 expression possibly contributing to the phenotype. Since the antidepressant effect of fluoxetine is discerned from neurogenesis, it is suggested that mechanisms other than adult neurogenesis underlie the therapeutic action of SSRIs in the HAB model, which, however, has to be confirmed by using additional SSRIs. Thus, the present data do not support the idea that neurogenesis is a prerequisite for therapeutic actions common to all antidepressants. Moreover, these findings highlight the importance of psychopathological animal models in order to investigate molecular mechanisms of effective antidepressants.

\section{Acknowledgements}

Supported by FWF DK SPIN WI206-B05.

Publish with Bio Med Central and every scientist can read your work free of charge

"BioMed Central will be the most significant development for disseminating the results of biomedical research in our lifetime. " Sir Paul Nurse, Cancer Research UK

Your research papers will be:

- available free of charge to the entire biomedical community

- peer reviewed and published immediately upon acceptance

- cited in PubMed and archived on PubMed Central

- yours - you keep the copyright

Submit your manuscript here:

http://www.biomedcentral.com/info/publishing_adv.asp 